Unter Umständen muss man zur Isolirung des Jods mit reiner Schwefelsäure oder alkoholischem Kali erhitzen und durch Natriumbisulfit reduciren.

Unter dem Namen Chinosol ') wird ein neues Antisepticum in den Handel gebracht. Bezüglich seiner Constitution steht es dem Diaphterin (Oxychinaseptol) sehr nahe; denn während nach Vulpius das Diaphterin als eine Verbindung von 1 Molecül Oxychinolin mit 1 Molecül phenolsulfosaurem Oxychinolin aufzuführen ist, besteht das Chinosol aus oxychinolsulfosaurem Kalium. $\left(\mathrm{C}_{9} \mathrm{H}_{6} \mathrm{~N}\right.$. OKSO $\mathrm{KSO}_{3}+\mathrm{xH}_{2} \mathrm{O}$.)

Es stellt ein krystallinisches, gelbes, in Wasser lösliches Pulver dar und besitzt einen aromatischen Geruch und ähnlichen, zusammenziehenden Geschmack. Um das Diaphterin vom Chinosol zu unterscheiden, genügt es das Präparat zu verbrennen, wobei das Diaphterin keinen Rückstand hinterlässt, während das Chinosol eine kalihaltige Asche liefert.

Unter dem Namen Pyrantin hat A. Pintti ${ }^{2}$ ) ein neues Fiebermittel vorgeschlagen, welches nach dem Resultate der klinischen und pharmakologischen Prüfung ein wahres Antidotum des Fieberprocesses sein soll, indem es die organische Oxydation durch indirecte Wirkung auf die Zellen und Gewebe vermindert.

Der Körper, das p-Aethoxylphenylsuccimid, wird erhalten entweder durch Schmelzen des salzsauren p-Amidophenetols mit Bernsteinsäure, oder des Phenacetins mit Bernsteinsäure und Ausziehen der Schmelze mit siedendem Alkohol.

Das Pyrantin krystallisirt in farblosen, prismatischen Nadeln, die bei etwa $155^{\circ}$ schmelzen; in Aether ist es unlöslich, löslich in 1317 Theilen Wasser von $17^{\circ}$ und in 83,6 Theilen Wasser von $100^{\circ}$.

Als Identitätsreactionen gelten folgende: Salzsäure oder schmelzendes Kaliumsulfat spalten das Pyrantin in p-Phenetidin und Bernsteinsäure, zur Erkennung des ersteren dient die Eisenchloridreaction.

$0,05 g$ Pyrantin in 2 bis $3 c c$ heisser, concentrirter Salzsäure gelöst und mit Wasser verdünnt geben auf Zusatz eines Tropfens 3 procentiger Chromsäurelösung eine rubinrothe Färbung.

Wird die wässerige Lösung der Kalischmelze des Pyrantins mit unterchlorigsaurem Calcium versetzt, so tritt eine allmählich zunehmende rothe Färbung auf.

1) Pharm. Ztg. 1896, S. 211 ; durch Pharm. Zeitschr. f. Russland 35, 174.

2) Apoth.-Ztg. 1896, S. 65 durch Pharm. Zeitschr. für Russland 35, 48. 
Wässerige Lösungen von Pyrantin werden durch Ammoniak und Chlorwasser hellgelb gefärbt. Sind Chininsalze zugegen; so nimmt die Fluorescenz derselben merklich $a b$, bei neuem Zusatz der Reagentien tritt beständige blaugrüne Färbung ein.

Alkalien fübren das Pyrantin in Salze der p-Aethoxylphenylsuccinaminsüure über, das lösliche Pyrantin ist das Natriumsalz dieser Säure.

3. Auf Physiologie und Pathologie bezügliche Methoden. Von

\section{F. Hofmeister.}

Verbesserte Methode zur Bestimmung des Harnstoffs mit unterbromigsaurem Natron. Alfred K. All en ${ }^{1}$ ) ermittelte, dass Zusatz von Kaliumcyanat zu Harnstofflösung die Ausbeute an Stickstoff bei dem Hypobromitverfahren sehr wesentlich steigert. Setzt man erst Cyanat und concentrirte Natronlauge zu verdünnter Harnstofflösung und lässt dann Bromlösung langsam einfliessen, so erhält man 99,8 bis $100 \%$ der geforderten Stickstoffmenge. Auf Grund dieses Verhaltens wendet Allen nachstehendes Verfahren auf den Harn an. $5 c c$ des zu untersuchenden Harns werden im Entwicklungsgefäss mit $0,250 \mathrm{~g}$ Kaliumcyanat und nach erfolgter Auflösung mit $25 c c$ einer 40 procentigen Natronlauge versetzt, dann nach Verbindung des Gefässes mit dem Nitrometer mittelst Scheidetrichters allmählich mit Bromlösung (2 g Brom in 16 ce einer 20 procentigen Bromkaliumlösung) zusammengebracht and das entwickelte Gas gemessen. Die Stickstoffentwicklung tritt sofort ein und ist gewöhnlich beendet, sobald die Hälfte der Bromlösung zugesetzt ist.

Die Bestimmung des Gesammtstickstoffs in Milch und Harn empfiehlt Léonard ${ }^{2}$ ) nach $\mathrm{Kjeldahl}$ in folgender Form auszuführen: $10 c c$ werden in einem $300 c c$ fassenden langhalsigen, zweckmässig durch einen Kupfermantel geschützten Kolben mit je $1 \mathrm{~g}$ wasserfreien Kupfersulfats und wasserfreien Dinatriumphosphats und mit $10 \mathrm{cc}$ concentrirter Schwefelsäure erhitzt, bis das Reactionsgemisch klar und blassgrün geworden ist. Die Bestimmung des gebildeten Ammoniaks kann dann in

1) Chemical News 73, 103.

2) Chemiker-Zeitung 20, Rep. 5 . 